\title{
Redefining Community Based Disaster Risk Management (CBDRM) through Enhanced Early Warning Processes
}

\author{
Maria Victoria G. Pineda, Member, IACSIT
}

\begin{abstract}
This is an exploratory study that contributed to the field of community-based disaster risk management (CBDRM), intently and carefully looking at how communities should react when an instance of an emergency or imminent disaster is to take place. Early warning is an action-trigger to any response consequence of any community.

Hence, this study intends to define and to underscore early warning as a critical element of a systematized CBDRM, devising strategies to empower the communities. The study also employed the concept of an affiliated crowdsourcing as a form of participation and an evolutionary method of SMS escalation in delivering effective early warning in a community.

The study entailed the design of a systematized prototype of a CBDRM to include early warning tools that permit alerting and reporting incidents or emergencies related to flooding and fire. The research study comes to a determination of a community-based early warning system in an urban setting and a set of processes that enable the citizens to take an active, participative and involved role. And while there are pertinent literatures on early warning systems, this paper intends to expand the concept of early warning.
\end{abstract}

Index Terms-Community based early warning, community guardianship, affiliated crowdsourcing, flood and fire, CBDRM.

\section{INTRODUCTION}

In March 1991, Mount Pinatubo, a sleeping giant volcano in the Central Luzon of the Philippines started to manifest brief earth tremors, a sign of an awakening. By June 15, 1991, Mt. Pinatubo, after 500 years of dormancy made one of the longest nine-hours eruption with large earthquakes, creating a caldera of 2.5kilometers in diameter. [1] Around 800 lives, hundreds of homes and billions of properties were lost. While there were tremors from mid-March to April, it was only 3-days before the actual eruption that it had manifested intermittent earthquakes. This had been the only sign, the warning of the imminent eruption.

The situation was aggravated by a typhoon passing by some 75kilometers northeast of Mount Pinatubo. Ref. [2] Pine [3] posited that a warning system should be a "means of getting information about an impending emergency, communicating the information to those who need it, and facilitating good decisions and timely response by people in

Manuscript received April 1, 2014; revised June 2, 2014. This research project was funded by the De La Salle University - University Research Coordination Office (DLSU-URCO) in Manila, Philippines. The publication of this paper was funded by the De La Salle Univeristy - Office of the President and Chancellor.

M. V. Pineda was with the Information Technology Department of the College of Computer Studies, De La Salle University, Philippines (e-mail: ms.victoria.pineda@gmail.com). danger". With complex situations and constricted information about the immediate hazard situations around, the damage could be enormous. In the case of Mount Pinatubo eruption, it affected over three hundred thousand families and 364 barangays.

In the December 2004 Indian Ocean tsunami, the U.S. government Pacific Tsunami Warning Center's seismometers detected seismic signals of a tsunami but it had "no sea-level data to detect or measure the system and no system for disseminating a warning". Likewise around the Indian Ocean, there were no tide gauges, seismometers or any communication systems that could serve as an early warning system [4].

Grasso [5] defined early warning as "the provision of timely and effective information, through identified institutions, that allow hazard-exposed individuals to be decisive to prevent or reduce their risk and prepare for a successful response". Gonzales [6] deemed early warning systems as "systems that warn officials of an impending danger by collecting and providing timely information of the incoming hazard to be used for communicating it to the public, to prepare them for the hazard's arrival, and to take actions to reduce the hazard risk." The 2004 tsunami incident took the lives of some 300,000 people because of lack of systematic early warning.

The Red Cross and the Red Crescent Societies define an early warning system as "the set of capacities needed to generate and disseminate timely and meaningful warning information to enable individuals, communities and organizations threatened by a hazard to community." Ref. [7] So to understand early warning, in a local context, it must be comprehended as a set of carefully planned tasks and communications, practiced and harnessed over a period of time. It is also notable to view early warning as a trigger to community guardianship. It is a technique that enables a community and its members to govern their actions that will protect and preserve the lives of their loved ones and their properties, to prepare and to act appropriately and in sufficient time to reduce the possibility of harm or loss.

\section{THE BARANGAY LEVERIZA}

Leveriza is one of the oldest communities in Manila, city capital of the Philippines. (Refer to Fig. 1 to see the map of Leveriza.) It has fifteen (15) barangays situated between the main thoroughfare Taft avenue and the Roxas boulevard. It is also adjacent to one of the oldest universities in the Philippines, the De La Salle University (DLSU) that recently marked 100years its existence in the country. At present, both Leveriza and DLSU are surrounded by many huge condominiums. 


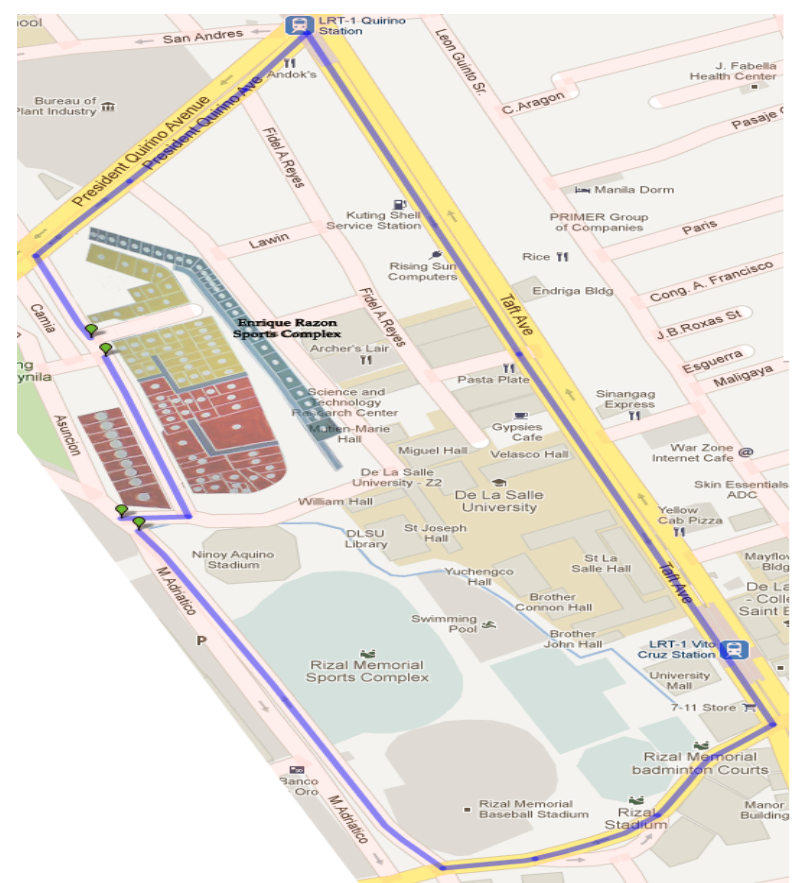

Fig. 1. The map of Leveriza, Manila.

Barangay 715 of Leveriza may be considered as the most open and participative in community partnerships. Bgy. 715 has been in the forefront in the sustainability seminars of the Assumption College and the emergency preparedness and disaster management seminar conducted by the De La Salle University.

Barangay 715 has an annual income of 1,101,206 pesos. It has 134 households, 469 in population where $6 \%$ is composed of elderly and citizens with special needs, $5 \%$ are aged 0-6years old. The neighborhood is densely populated by small houses with narrow streets. There are also surrounding canal waterways [8].

To date, the barangay and the whole of the Leveriza neighborhood had been greatly affected by flooding that took place in 2009, when Typhoon Ketsana (local name Ondoy) devastated the whole of Metro Manila and Typhoon Nesat (local name Pedring) in 2011.

At present, the officials of the barangay have diligently attended the seminars on Disaster Management conducted by the national government. Through the efforts of the Barangay Chairman, demographics of the community members had been collected and an evacuation plan had been designed.

In a survey conducted in the last seminar, the 22 community members would have the following profile:

1) All of them have mobile phones with brands such as Nokia, Samsung, Cherry Phone and MyPhone.

2) Those who access the internet are aged 27 and below using Yahoo for email, Facebook and Youtube.

3) In a survey of environmental threats, they find theft and fire as top risks.

4) At an average the members spend 15 to 30 pesos a day for the mobile phone service.

5) They rely on television and radio as the main disseminator of typhoon or weather announcements.

6) They are contented and generally happy on the services and activities provided by the Barangay officials.

Fig. 2 is an infographic of the responses of some of the active community members of Barangay 715 .

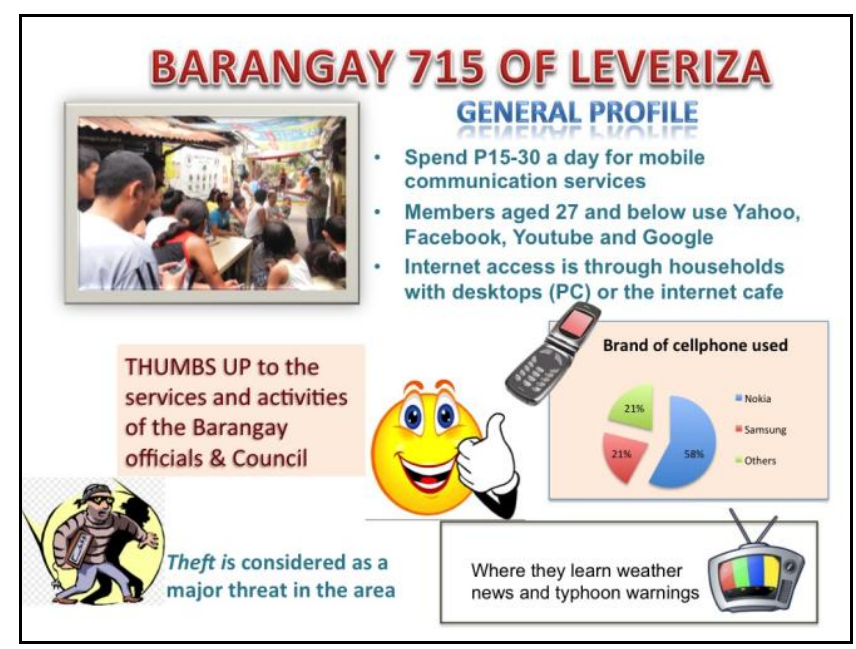

Fig. 2. An infographic describing the responses of the Bgy. 715 constituents

\section{RESEARCH DESIGN}

\section{A. Early Warning Models}

Earlier studies on early warning made use of a three-step model-monitoring of the precursors, forecasting of a probable event and notification of the alert or the warning. In a thorough study by Villagran De Leon and Bogardi, they translated this three-step model to add and enhance it through an introduction of technical capacity. They devised a four-step model to include - risk knowledge, warning service, communication and dissemination, and response capability. [9] In this model the authors emphasized the need to build the necessary skills among the citizens to understand, heed a warning, and to perform the necessary actions. This model also recognized that early warning systems vary depending on types of hazards and exposures of the people. Similarly, the Grasso model has risk knowledge, monitoring and predicting, disseminating information and response. Risk knowledge is the provision of the right information that leads to mitigation priority strategies. Monitoring and predicting is the generation of capacities to provide hazard approximations that threatens the communities, the economies and the environment. Information dissemination emphasizes dependable, consistent and simplified information for those in authority and the constituents. Finally response is a bundled set of actions such as governance, coordination, suitable response plans and empowerment of the members to take actions when a disaster is about to take place. [5] The model emphasized the crucial task of translating the prediction into a useful warning. Otherwise the model fails.

These models were carefully examined with consideration to strong floods and recent fires that have disturbed the Leveriza area. The Grasso model was adopted in the design with consideration of the other pertinent literature and methodologies.

This is an exploratory study that attempted to expand the understanding of early warning systems while earlier views in this field had been constricted and dependent to environmental conditions or warnings. The study designed and developed a prototype of a community-based web information system to support the barangay in their early warning methods and strategies. 


\section{B. Concepts and Models Incorporated in the Design}

The web-based information system conceived followed a model that blended community based disaster risk management system (CBDRMS) concepts and social learning; careful application of crowdsourcing technique to the early warning process and perceptive selection of mobile technology as a tool; and inclusion of human-centric sensing.

In most community-based disaster risk management (CBDRM) studies, importance of community profiling, risk and hazard assessments, incident reporting and training management are emphasized. [10] These major processes contribute to the understanding and practice of preparedness and resiliency among many communities especially in the low-income areas. Victoria also posited that in a community based disaster management it is noteworthy to highlight people's participation, priority for the most vulnerable groups, families and people in the community, risk reduction measures that are community specific, and existing coping mechanism and capacities recognized. [11] Community-based disaster risk management (CBDRM) is essential in making a community become aware and understand its own vulnerabilities and devising ways and methods, using its own resources to address any known or imminent hazard. This concept was employed to determine the community's vulnerabilities.

Social learning on the other hand refers to sharing good practices and collectively learning from the practices with or without the use of technology. This leads to improved participation and involvement in the community and possibly turning into a community of practice (COP). [12] Social learning is desired to enhance the connections, exchange of know-hows and relationships in the community.

Crowdsourcing is a paradigm of having collective ideas join or cross each other to arrive at better problem solving or decision-making. [13] This could very well address the basic issue - who is responsible in alerting or reporting the conditions and incidents at the street or barangay level? The task cannot be exclusive to the barangay officials because they do not serve $24 / 7$ or 24 hours in the barangay. The task must be shared to the members of the community. A better way to do this is to devise an affiliated-type crowdsourcing where the volunteers and members reporting are affiliated and know each other. This has also led and inspired the design of the early warning reporting process.

"Technology is a sticky chemistry that increases social responses of the community members making them information and communication armed citizens. " [10] The habitual use of the technology such as the mobile phone that builds a human-centric-sensing skill among the community members to become self-directed, confident but responsible in reporting incidents and taking roles in the early warning process. Human-centric sensing skill is an important resilient character to be developed in the communities.

Fusing together social learning and affiliated crowdsourcing utilizing technology is a present-day technique to enable a systematized CBDRM.

\section{THE REPORTING PROCESS}

Based on the survey, the mobile phone is the most practical and widely used tool among the community members. The selection of the mobile technology and the short messaging system (SMS) for conventional reporting in the web front-end application had been deemed to become effective together with the affiliated crowdsourcing.

Fig. 3 shows the main page of the web-based CBDRM information system labeled as Thera Praevenio (ThP).

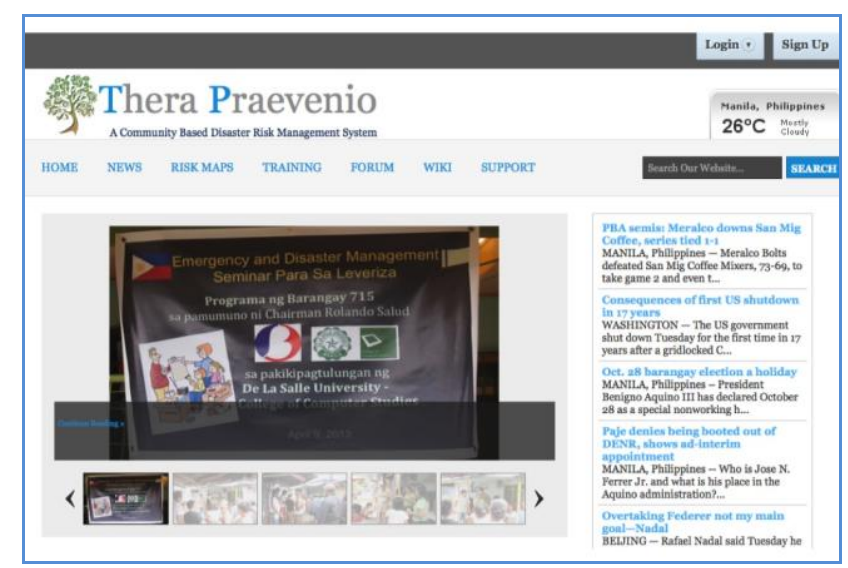

Fig. 3. The Thera Praevenio main page: http://leveriza.org.

The major processes that were created are the:

1) Registration: This is intended to account the community members, interested parties and volunteers around the vicinity and the support services like hospitals and fire brigades and the local government.

2) Mobile reporting: This is intended to alert, report, update, monitor and record all instances from the trigger of the early warning until it ceases the incident or is put into closure.

Mobile reporting and/or escalation of emergencies or related incidents may be performed in the following ways:

- When a typhoon signal is received from the PAG-ASA, the government weather agency, the Thera Praevenio blasts a typhoon signal warning. A blast is an SMS (short messaging system) notification sent to all subscribed community members and barangay officials. This straightforward reporting is shown in Fig. 4.

- When an incident such as smoke possibly indicating fire or a flood starting at the ankle is spotted, any subscribed member can send a report to ThP. The Thera Praevenio with its operator in the barangay sends an SMS to its constituents to the reported area to confirm the reported incident. Once a confirmation is received, ThP sends a blast to all the subscribed members. An example of this process is shown in Fig. 5.

- When an incident similar to Step b. occurs and there is no operator in the barangay, Thera Praevenio alerts the barangay official in-charge through the mobile phone using the ThP application. The barangay official initiates a confirmation with its constituent members (serving as volunteers or barangay officials) residing in the affected area. Once a confirmation is received, the barangay official can issue an official blast alert to the community. The process is shown in Fig. 6.

- In the occurrence of step $\mathrm{C}$, there will be continuous monitoring and reporting of the situation to its members until a closure of the incident takes place. The web hazard map of ThP is activated and any interested party 
would be able to view the status of the incident, fire or flood, in the web. Affiliated agencies and units: the local government or the office of the Vice-Mayor, the nearby hospital or fire services will be alerted as well. This step is showcased in Fig. 7.

\section{The straightforward warning}

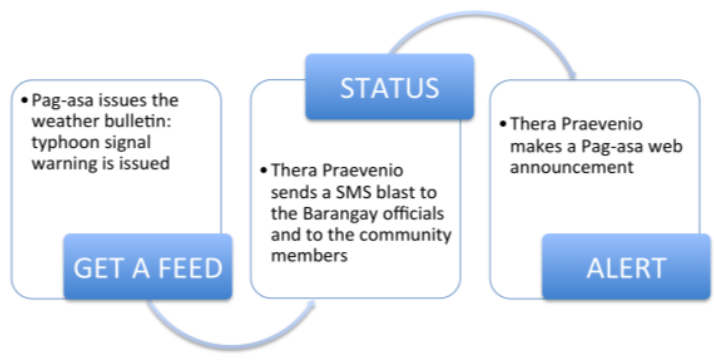

Fig. 4. The Straightforward typhoon signal announcement.

\section{Member reports/confirms the incident (e.g. in Barangay 705)}

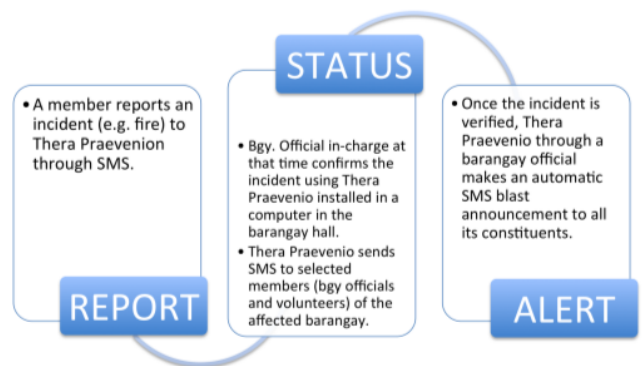

Fig. 5. Reporting of an incident like fire.

\section{Member remotely alerts the members}

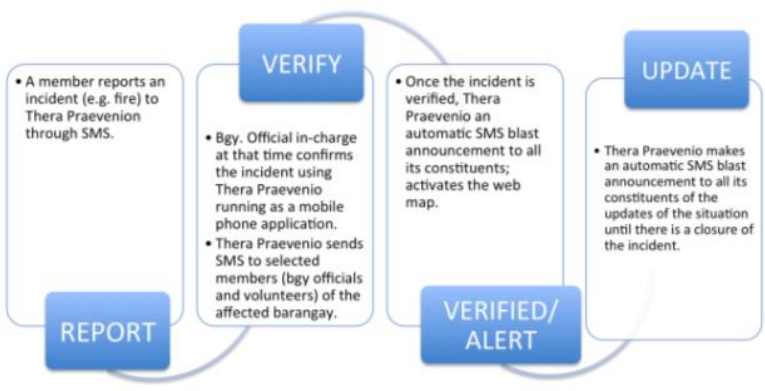

Fig. 6. Another example of escalating an incident.

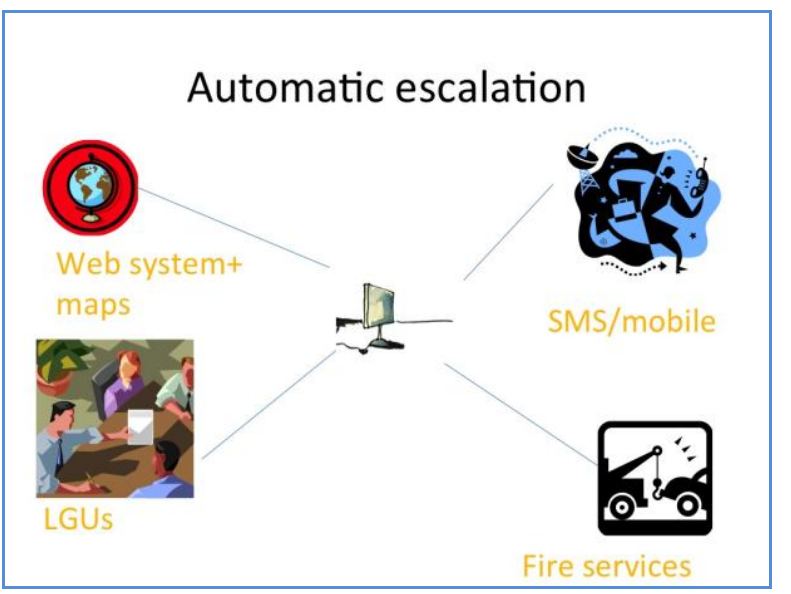

Fig. 7. Thera Praevenio automatically alerting respective response agencies.
TABLE I: THE MOBILE REPORTING CODES TO BE USED BY THE COMMUNITY MEMBERS IN REPORTING AN EMERGENCY INCIDENT

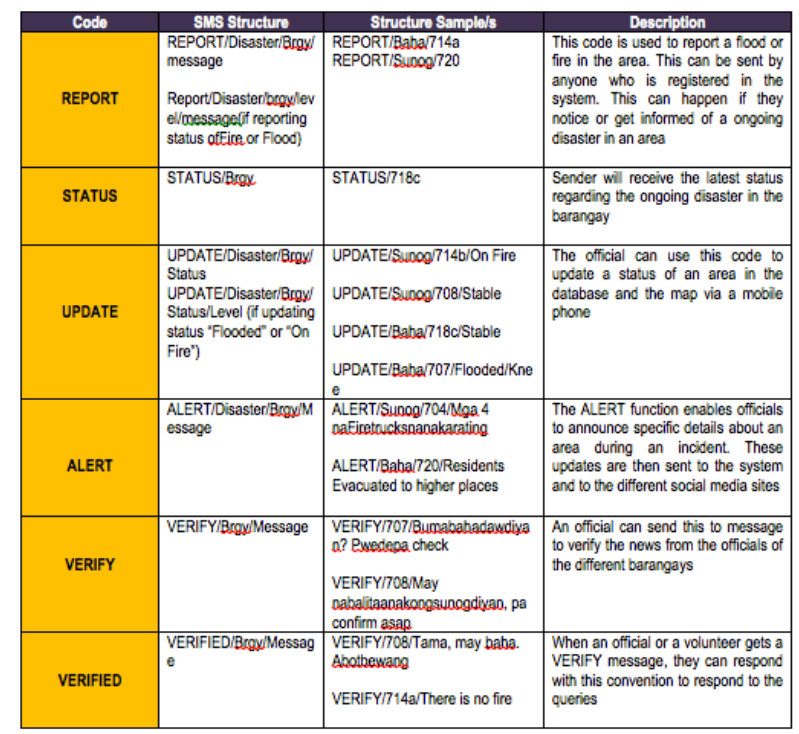

Table I lists the different SMS codes to be adhered by the community members.

3) Hazard mapping: There are two hazard maps available to the users, namely, the flood map and the fire map. The fire map would have two statuses, the smoke and the flame. While the smoke indicates a probable or suspected start of a fire, the flame signifies or applies to a longer, heavier fire situation. An example of the fire indicator is Figure 8.0. Flood maps on the other hand would exhibit the status of the area if it is flooded and the last reported height of the flood. Floods are conveniently estimated (following the average heights of the Filipinos) as ankle level, knee level, waist level or chest level. The maps can be publicly viewed in the website.
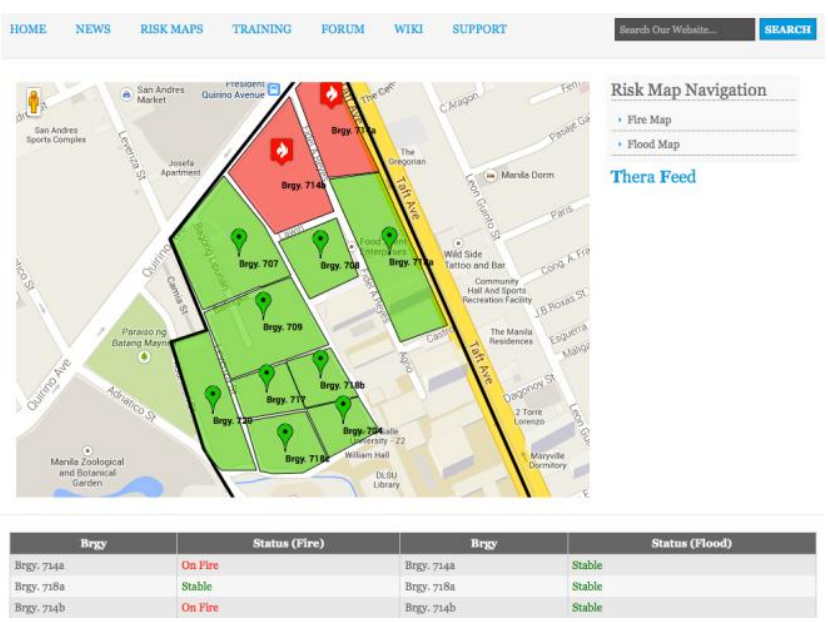

Fig. 8. The hazard map of Thera Praevenio showing the status of fire.

4) Training in Wiki: This feature encourages the members to plan in advance their training requirements based on past experiences.

5) Reports: This is intended to track all related incidents and notifications performed during a flood or fire.

\section{RESULTS AND ANALYSIS}

While there are agencies that are in-charge of giving 
weather or storm updates, there is an immense need to be able to monitor real-time incidents occurring within the community that may stricken or harm any member, be it in the form of flooding and/or fire. More so, if there are incidents such as theft or riot that are not forecasted by national agencies. In this perspective that there is a need to strengthen the community based involvement whereby the constituents turn to become human sensors. Equipped with their training on flooding and fire hazards and their training on mobile phones' customized short messaging system (SMS) reporting to the barangays, the community guardianship from any hazard is not far fetched.

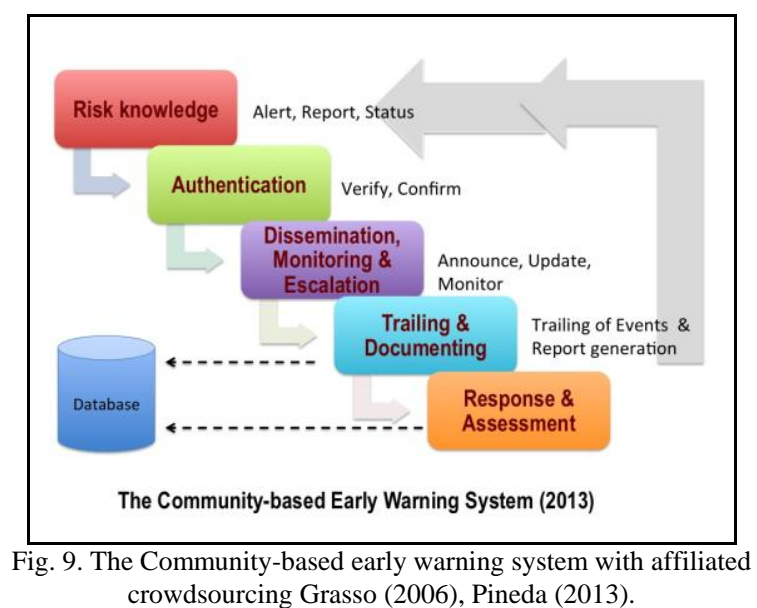

The study led to an improved model of Grasso's early warning that incorporates affiliated crowdsourcing and highlights the importance of authentication in the reporting flow as shown in Fig. 9. It hastens the verification of the incident because the reporting person is somebody registered to the system.

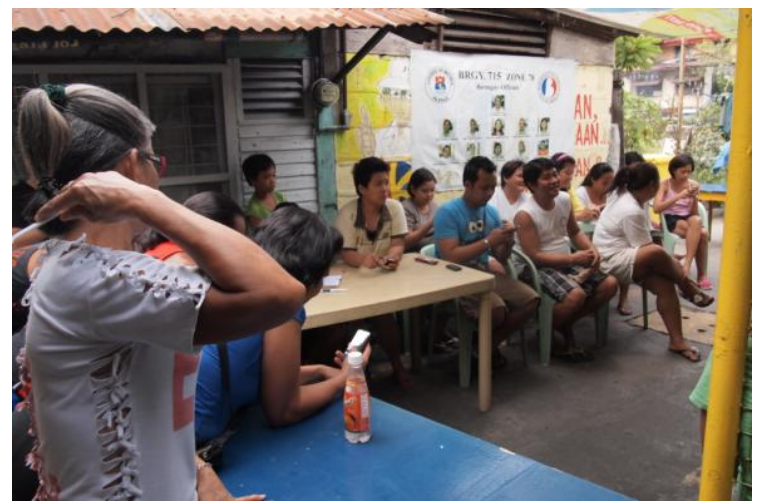

Fig. 10. The seminar delivered in Bgy. Leveriza teaching the SMS reporting codes and techniques.

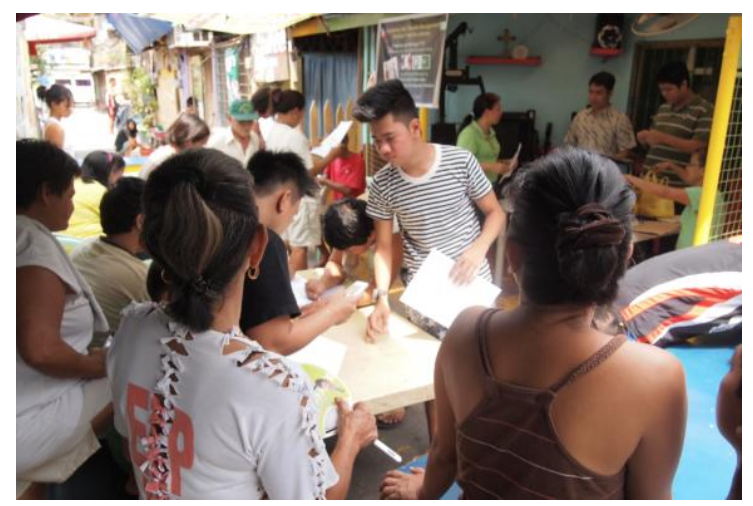

Fig. 11. The members of Bgy. Leveriza responding to the survey.
Blending CBDRMS and social learning with the interplay of mobile technologies and reporting strategies paved way to an enabled community, not just sharing but coaching one another to effectively use the mobile phone to report incidents and pass on information.

This became evident during the seminar delivered by the principal researcher. Fig. 10 shows the beginning of the seminar on emergency management. The seminar tackled basic concepts of disasters in the Philippines, the concept of human-centric reporting and how each member can become involved. The seminar also led the group to different ways of using SMS to submit a message or report an incident and how it can be translated to a set of conventional keywords such as alert, confirm, report or update to provide a brief, truthful condition of an incident such as fire or flood at a given time. The seminar generated a high level acceptance and the use of the mobile phone as a tool is a smart and naïve way of convincing the people that they can contribute and participate. Fig. 11 shows the community members evaluating the seminar activity.

Affiliated crowdsourcing as a strategy works in a community because it holds the members accountable to the reporting that they perform. Once the members see that such approach works, the higher involvement of the people will be seen and a more evident human-centric sensing attitude.

\section{CONCLUSIONS}

The significance of this study is that it realizes the need for early warnings at the ground level. It is not enough to have feeds coming from weather agencies. These offices can just forecast an upcoming typhoon. But actual incidents of fire or flood which are experienced and witnessed right away at the street level, can be immediately reported by the constituents of the community.

The concept of early warning will only work if the community members as main actors initiate and perform the necessary action when an imminent threat occurs. The community members themselves performing the crowdsourced reports now turn into human sensors. The alerts, reports, verification, monitoring and even escalation are performed by the participating citizens themselves, augmented and supported by the evolutionary SMS real-time reporting and recording.

This is the modern-day community guardianship. The community realizes that early warning is also an action-trigger to any response consequence of any community. How prepared and organized the community would be will deliver better response results.

Since the crowdsourcing strategy is decentralized in terms of getting data, actual warnings and alerts are disseminated faster, concerned agencies are alerted and can extract data from the public web information.

Based on this experience, the research project deemed the following as required characteristics of an effective community based early warning system:

1) It provides ample time to react;

2) It is knowing what to do ;

3) It allows to perform the necessary action;

4) It is highly participatory and shared risks; 
5) It is able to verify information;

6) It permits warning and information to be shared;

7) It alerts other stakeholders;

8) It monitors, tracks and record the incident;

9) It saves lives and properties;

10) It is a continuous, shared practice.

In this study, community-based early warning system is a set of well-planned, timely reporting strategies, tasks, technology tools and the citizens serving as central sensors in the process to mitigate risks, save lives and properties. The study presented that a community-based early warning system can be strengthened by a well-defined set of reporting processes and use of ICT and the enhancement of the community guardianship concept through the shared involvement and participation of the members. The study also recognized that affiliated crowdsourcing is a very good technique to decentralize tasks and make the community members co-own the reporting process.

The project also redefined the early warning framework with the inclusion of a) an authentication of warning and information in the community level, b) the need to assess the performance delivered by the community and c) to store the incidents and experiences for future references.

While the initial user tests proved the design works effectively, improvements and polishing of the mobile reporting application are needed to ensure stable interfacing with the web-based information system and more tests together with the community members must be preformed.

It is the recommendation of this study for the local governments to venture on this kind of projects, organizing the communities to manage and customize their own CBDRM and further increase community resiliency. It is also recommended to expand CBDRMS and community-based early warning system studies to include planning of response and rescue of people with special needs, people with impairment and the elderly in the community.

\section{ACKNOWLEDGMENT}

This research project was funded by the University Research Coordination Office (URCO) of the De La Salle University and the De La Salle Science Foundation. The publication was funded by the Office of the President and Chancellor of DLSU. The principal investigator of the research had been very grateful to the support of URCO-DLSU. This project was granted last December 2012 and was completed this last quarter of 2013.

The author also wishes to acknowledge the development of the prototype and the initial review of early warning systems performed by Jad Gonzales, Angelo Arnaldo, Calvin Ongkiko and Wesley Marquez-Lim. The author also expresses appreciation to the cooperation of Barangay 715 of Leveriza under the leadership of Bgy. Captain Rolando Salud.

\section{REFERENCES}

[1] M. Rosenberg. Mount Pinatubo Eruption. [Online]. Available: http://geography.about.com/od/globalproblemsandissues/a/pinatubo.ht $\mathrm{m}$
[2] E. De Guzman. (1992). Eruption of Mount Pinatubo in the Philippines in 1991. ADRC (Asian Disaster Reduction Center) Report. [Online]. Available:

http://www.adrc.asia/publications/recovery_reports/pdf/Pinatubo.pdf

[3] J. C. Pine, Technology in Emergency Management, Wiley, 2007.

[4] L. Valigra. (2005). Indian Ocean's Tsunami Early Warning System Taking Shape. The National Geographic News. [Online]. Available: http://news.nationalgeographic.com/news/2005/12/1223_051223_tsun ami_warning.html

[5] V. F. Grasso. (2006). Early Warning Systems: State-of-Art Analysis and Future Directions. United Nations Environment Programme (UNEP). [Online]. Available: http://na.unep.net/geas/docs/Early_Warning_System_Report.pdf

[6] J. Gonzales, A. Arnaldo, W. Marquez-Lim, C. Ongkiko, and M. V. Pineda, "Designing a community based early warning and mapping system for an urban barangay," presented in the DLSU Research Congress, March 2013.

[7] IFRC. (2013). Community Early Warning Systems: Guiding Principles. International Federation of Red Cross and the Red Crescent Societies, Geneva. [Online]. Available: http://www.ifrc.org/PageFiles/103323/1227800-IFRC-CEWS-Guidin g-Principles-EN.pdf

[8] Handout on CBDRM, Profile of Barangay Leveriza, 2012.

[9] J. C. Villagran de Leon and J. Bogardi. (2006). Early Warning Systems in the Context of Disaster Management. United Nations University-Institute for Environment and Human Security. [Online]. Available:

http://www.unisdr.org/2006/ppew/info-resources/docs/ELR_dt_23-25 .pdf

[10] M. V. Pineda, "Exploring the Potentials of a Community-Based Disaster Risk Management System (CBDRMS), the Philippine Experience," International Journal of Innovation, Management and Technology, vol. 3, no. 6, pp. 708-712, 2012.

[11] L. Victoria. (2010). Community based disaster management in the Philippines: making a different in people's lives. Asian Disaster Preparedness Center. [Online]. Available: http://www.preventionweb.net/files/733_8363.pdf

[12] M. V. Pineda, "Actualizing communities of practice (COPs) and situated learning for a sustainable eco-village," in Proc. International Proceedings the 2nd International Seminar on Eco-settlements, ISBN 978-602-8330-46-6, pp. 585-590, the Research Institute for Human Settlements Indonesia.

[13] J. Howe, Crowdsourcing, Three Rivers Press, 2008.

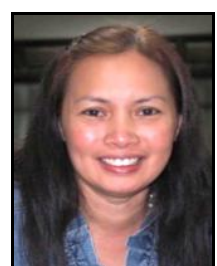

Maria Victoria G. Pineda was born in Manila, Philippines. She took the bachelor of science in information and computer science from Saint Paul College Manila. She took M.A. in educational management in 1994-1998 in De La Salle University and M.A. in communication studies from 2004-2006 also in De La Salle University in Manila. She was a Lecturer and researcher in the Information Technology Department of the College of Computer Studies, De La Salle University in Manila, Philippines.

Her research work on CBDRM (community-based disaster risk reduction) started in early 2009. She had several publications on disaster management and had pioneered the said research area in the Information Technology Department of DLSU. She is still engaged with the communities that have been involved in her studies: the Jaime Hilario Mission School of Bagac, Bataan; the Buklod Tao community-based organization in San Mateo, Rizal; and the Barangay 715 of Leveriza in Taft Avenue, Manila. All these communities are in the island of Luzon, Philippines.

She is currently an independent consultant on e-learning, $21^{\text {st }}$ century rhizomatic learning models, open teaching, web tools and community based disaster risk reduction and management. She is presently a member of the Board of Trustees of the Philippine e-Learning Society. She also delivers workshops, lectures, seminars and webinars. Her current projects include the instructional design and conversion of traditional courses to blended learning approach for the graduate school and the BPO industry and ICT capacity building of teachers. 